\title{
UPDATE Verbal and novel multisensory associative learning in
}

\section{adults [version 2; peer review: 2 approved]}

\section{Joanne M Fifer ${ }^{1}$, Ayla Barutchu³, Mohit N Shivdasani², Sheila G Crewther ${ }^{1}$}

${ }^{1}$ School of Psychological Science, La Trobe University, Bundoora, 3086, Australia

${ }^{2}$ Bionics Institute, Melbourne, 3002, Australia

${ }^{3}$ Florey Institutes of Neuroscience and Mental Health, University of Melbourne, Melbourne, 3010, Australia

V2 First published: 07 Feb 2013, 2:34

https://doi.org/10.12688/f1000research.2-34.v1

Latest published: 28 May 2013, 2:34

https://doi.org/10.12688/f1000research.2-34.v2

\section{Abstract}

To date, few studies have focused on the behavioural differences between the learning of multisensory auditory-visual and intra-modal associations. More specifically, the relative benefits of novel auditoryvisual and verbal-visual associations for learning have not been directly compared. In Experiment 1, 20 adult volunteers completed three paired associate learning tasks: non-verbal novel auditory-visual (novel-AV), verbal-visual (verbal-AV; using pseudowords), and visualvisual (shape-VV). Participants were directed to make a motor response to matching novel and arbitrarily related stimulus pairs. Feedback was provided to facilitate trial and error learning. The results of Signal Detection Theory analyses suggested a multisensory enhancement of learning, with significantly higher discriminability measures (d-prime) in both the novel-AV and verbal-AV tasks than the shape-VV task. Motor reaction times were also significantly faster during the verbal-AV task than during the non-verbal learning tasks. Experiment 2 ( $n=12$ ) used a forced-choice discrimination paradigm to assess whether a difference in unisensory stimulus discriminability could account for the learning trends in Experiment 1. Participants were significantly slower at discriminating unisensory pseudowords than the novel sounds and visual shapes, which was notable given that these stimuli produced superior learning. Together the findings suggest that verbal information has an added enhancing effect on multisensory associative learning in adults

\section{Keywords}

associative learning, multisensory integration, audition, vision, verbal
Open Peer Review

Approval Status

1

2

version 2

(update)

28 May 2013

version 1

$07 \mathrm{Feb} 2013$

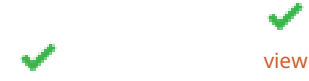

1. Chris Baker ID, National Institute of Mental Health, National Institutes of Health,

Bethesda, MD, USA

2. Trevor Hine, Griffith University, Queensland, Australia

Any reports and responses or comments on the article can be found at the end of the article.

This article is included in the Real-life cognition

collection. 
Corresponding author: Sheila G Crewther (s.crewther@latrobe.edu.au)

Competing interests: No competing interests have been declared.

Grant information: We wish to thank Neville and Di Bertalli for their financial support of this study. The Bionics Institute acknowledges the support it receives from the Victorian Government through its Operational Infrastructure Support Program.

The funders had no role in study design, data collection and analysis, decision to publish, or preparation of the manuscript.

Copyright: @ 2013 Fifer JM et al. This is an open access article distributed under the terms of the Creative Commons Attribution License, which permits unrestricted use, distribution, and reproduction in any medium, provided the original work is properly cited. Data associated with the article are available under the terms of the Creative Commons Zero "No rights reserved" data waiver (CC0 1.0 Public domain dedication).

How to cite this article: Fifer JM, Barutchu A, Shivdasani MN and Crewther SG. Verbal and novel multisensory associative learning in adults [version 2; peer review: 2 approved] F1000Research 2013, 2:34 https://doi.org/10.12688/f1000research.2-34.v2

First published: 07 Feb 2013, 2:34 https://doi.org/10.12688/f1000research.2-34.v1 


\section{UPDATED Changes from Version 1}

Acting on the advice of Trevor Hine, the formula used to calculate $\mathrm{d}$-prime has been included. The d-prime statistic was calculated as the $z$ score difference between hit and false alarm rates [i.e. d-prime $=Z$ (hit rate) $-Z$ (false alarm rate) $]$. We have also fixed the typo on page 7 (i.e., $p<$ was changed to $p>0.05$ ) to read "No significant differences were found between MRTs for the three black symbol sets, $F(2,22)=1.36, p>0.05$, partial $\eta^{2}=0.11^{\prime \prime}$.

See referee reports raises the question of whether visual-verbal learning may lead to behavioural advantages when compared with non-verbal auditoryvisual learning in adults. The association and transfer of visual and verbal information are of particular relevance, as such associations are known to play an important role in the acquisition of complex cognitive tasks, such as reading ${ }^{24-26}$. Furthermore, in infants, linguistic material such as nonsense words can enhance associations between stimuli and contribute to categorical learning ${ }^{27,28}$. However, to the best of our knowledge, no study has directly contrasted the learning of visual-verbal associations with non-verbal auditoryvisual associations in adults.

\section{Experiment 1}

The current study addressed two aspects of multisensory associative learning. Firstly, we aimed to evaluate performance differences on analogous intra-modal and multisensory learning tasks. Secondly, we further aimed to compare verbal and non-verbal multisensory associative learning. Three paired associate learning tasks were created: novel non-verbal auditory-visual (employing "novel sounds"; novel-AV), verbal-visual (verbal-AV), and visual-visual (shapeVV). We used a trial-and-error learning paradigm based on that of Tanabe et $a l .^{20}$, but with concurrently presented stimuli, in order to examine differences in associative learning between multisensory and intra-modal stimulus pairs under simultaneous conditions. The novel-AV and shape-VV tasks utilised non-verbal stimuli, whereas the verbal-AV task included auditory pseudowords to evaluate the impact of semantically novel, yet phonetically familiar, auditory stimuli on learning. Learning performance and task differences were evaluated by analysing changes in accuracy using signal detection theory (d-prime) and motor reaction times (MRTs).

\section{Materials and methods}

\section{Participants}

Twenty right-handed adults (9 males), between 18 and 35 years of age $($ mean $=24.87$ years, $\mathrm{SD}=3.54)$ were recruited. All participants spoke English as a first language and were screened to ensure auditory detection thresholds and vision (distance, near and colour) were within the normal or corrected to normal ranges. Participants reported no history of neurological or psychological disorders. Estimated Full Scale IQ scores on the Wechsler Test of Adult Reading ${ }^{29}$ were above the $10^{\text {th }}$ percentile for all participants except one adult, whose results were excluded from further analyses. Written informed consent was obtained from all participants. Ethics approval was obtained from the La Trobe University Human Research Ethics Committee, Bundoora, and The Royal Victorian Eye \& Ear Hospital Human Research Ethics Committee, Melbourne.

\section{Associative learning tasks}

Four novel and arbitrarily related stimulus pairs were created for each learning task (novel-AV, verbal-AV and shape-VV). All auditory and visual stimulus pairs were presented well above threshold, and were therefore easily detectable. Visual black symbols (BS) of 3 degrees of visual angle, composed using black lines against a white background (see Figure 1: BS1, BS2, BS3 for examples), were presented at participants' central fixation point on a 22-inch cathoderay-tube (CRT) monitor (positioned at a distance of 1 meter from participants). These visual symbols were paired either with novel
Other empirical evidence indicates that concurrently presented familiar cross-modal stimulus pairs with verbal components can influence both learning and multisensory processes ${ }^{1,14,15,21}$. Indeed, verbal stimuli have been shown to facilitate many cognitive processes, including object categorisation and localisation ${ }^{22,23}$. This 


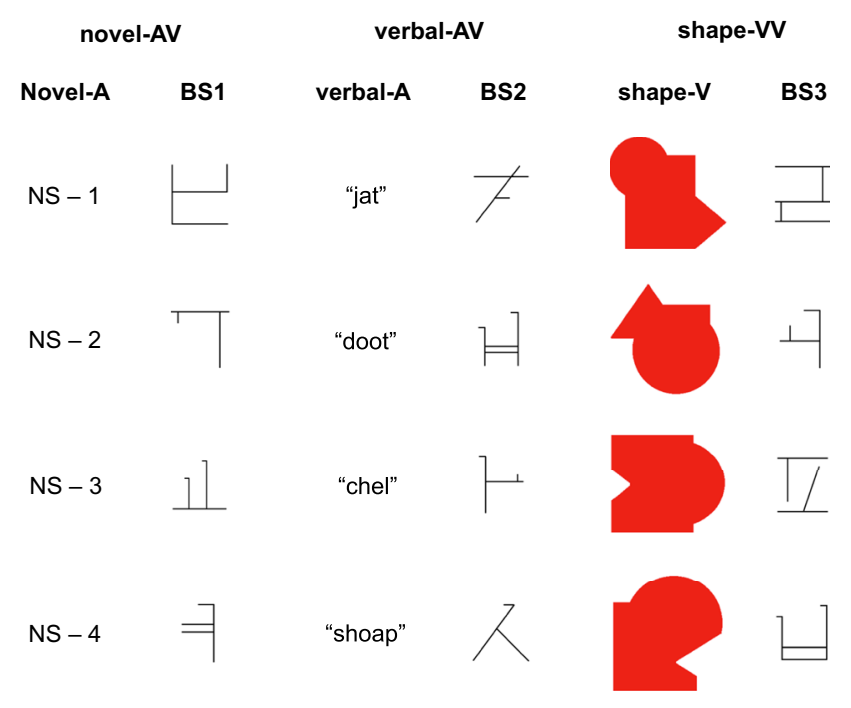

Figure 1. Auditory and visual stimuli of associative learning tasks. Auditory and visual stimuli for the novel sound-visual (novel$A V)$, the verbal-visual (verbal-AV), and the visual-visual (shape-VV) associative learning tasks.

sounds that were unfamiliar and could not be vocalised (novel-AV), verbal pseudowords (verbal-AV), or other visual symbols (shape-VV) (see Figure 1 for an illustration of all stimuli used).

For the novel-AV task, novel non-speech auditory sounds were digitally created (sampling rate $=48.8 \mathrm{kHz}$, duration $\sim 620 \mathrm{~ms}, 5 \mathrm{~ms}$ rise-fall time), consisting of combinations of four amplitudemodulated tones using different carrier and modulation frequencies. In the novel-AV task, for each novel sound, the carrier frequencies ranged between 400-480 $\mathrm{Hz}$ (novel sound 1; NS-1), $1000-1350 \mathrm{~Hz}$ (NS-2), 3000-3200 Hz (NS-3) and 250-4500 Hz (NS-4). Modulation frequencies were either kept at $3 \mathrm{~Hz}$ (NS-1), $10 \mathrm{~Hz}$ (NS-2), $0.5 \mathrm{~Hz}$ (NS-3) or $6 \mathrm{~Hz}$ (NS-4). In addition to the amplitude modulated (AM) tones, two pure tones of $250 \mathrm{~Hz}$ and $450 \mathrm{~Hz}$ were also added to NS-4. In the verbal-AV task, four single syllable pseudowords (matched for the duration of $\sim 620 \mathrm{~ms}$ ) pronounced by a young female adult were used ("jat", "doot", "chel" and "shoap"). Each pseudoword began with a different consonant to emphasise stimulus onset. Pseudowords were pre-recorded in a sound attenuated recording booth (sampling rate $=48.8 \mathrm{kHz}$ ). All verbal and novel-sounds were presented at $69 \mathrm{~dB}$ sound pressure level (SPL) using closed headphones. The shape-VV task employed a second visual stimulus, which was a novel solid red shape constructed by overlaying rectangular, triangular and circular shapes in different combinations (see Figure 1, shape-V). In this task the black symbol was presented superimposed and contained within the red shape such that both were presented at the participant's central fixation point. All stimulus pairs were presented concurrently for the duration of $\sim 620 \mathrm{~ms}$ with simultaneous onset and offset times.

Sound files used in the experiments

http://dx.doi.org/10.6084/m9.figshare.154795
Participants were required to learn the associations between the stimulus pairs via trial and error. Figure 2 presents a schematic diagram of the temporal sequence of a single trial. For each task, matching stimuli were four specific pairings of stimuli, out of a possible 16 stimulus combinations. The non-matching stimuli comprised the 12 other possible pairings of the stimuli. Each learning task was administered as four blocks of 32 trials (128 total trials). In $50 \%$ of the trials, matching pairs were presented, and the remaining trials consisted of non-matching stimuli. The presentation of stimulus pairs within each block was pseudorandom, such that each block consisted of 16 presentations of matching stimuli with each stimulus pair presented four times. Participants were instructed to make a button response with their right index finger when a matching stimulus pair was detected. A 'no response' was deemed to be an indication that the participant did not consider the stimuli to be a matched pair. Participants were allowed $3000 \mathrm{~ms}$ to respond, after which feedback was provided after every trial using an ascending tone burst (for a correct response) or descending tone burst (for an incorrect response), presented for a duration of $200 \mathrm{~ms}$. The feedback was followed by an inter-stimulus interval, which randomly varied between 1000 to $2000 \mathrm{~ms}$.

\section{Procedure}

Participants completed the three tasks in a quiet room. Testing took place over one or two sessions, and the total test time per participant was approximately 2 hours. When two or more learning tasks were completed in a single session, a period of at least 45 minutes was implemented in-between tasks to maximise concentration for the subsequent learning task. During this time, the auditory and visual screening tasks were completed. The order in which the three learning tasks (novel-AV, verbal-AV, and shape-VV) were administered was counterbalanced across participants.

A practice task was employed prior to each experimental learning task. The practice task was analogous to the proceeding experimental task; however, there were only three stimulus pairs (as opposed to four), and the stimuli were not abstract (e.g., visual stimuli were images of a square, circle and triangle rather than unfamiliar shapes). Participants were encouraged to ask questions about the practice task and up to 60 trials were administered until such time as the participant demonstrated understanding of the task requirements. In addition, immediately before the experimental tasks began, participants were presented once with each of the eight individual stimuli that made up the four stimulus pairs. This familiarisation process ensured that participants were aware of the characteristics of each stimulus, but did not receive any information regarding whether they were matching or not. Participants were instructed that

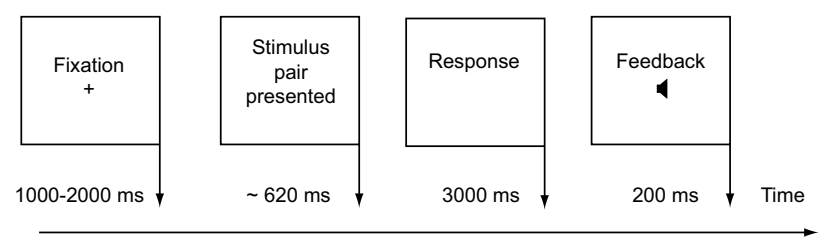

Figure 2. Example trial of the associative learning task. Temporal sequence of a single experimental paired associate learning trial. 
during the experimental task they would be shown novel symbols, for which they would need to learn the associated pseudowords (verbal-AV), sounds (novel-AV), or shapes (shape-VV). Each of the four blocks within each task was of approximately 4 minutes duration, and participants were offered a short break of up to 1 minute between blocks.

\section{Data analysis}

Accuracy data and motor reaction times (MRTs) were recorded. An error on a matching trial was a failure to make a motor response (i.e., miss). A motor response to a non-matching trial reflected a false alarm. Only the first 120 trials were analysed, as some participants failed to complete the entire set of 128 trials due to computer failure (only one participant on the verbal-AV condition was affected). All participants completed the first 120 trials that were analysed.

To visualise the different patterns of learning across trials for each task and stimulus pair type, "five-point moving average" analyses were employed to construct learning curves consisting of 116 overlapping windows moving in one trial steps, which were averaged across participants. Sets of five trials were used because preliminary analysis revealed that considerable learning occurred early in the experiment, and small window lengths allowed for optimal visualisation of learning effects.

Signal Detection Theory (STD) and measures of discriminability (d-prime) were used to assess changes in learning trends for the three stimulus pair types. The discrimination statistic, usually known as d-prime, is a measure of an individual's ability to distinguish true signals from noise ${ }^{30,31}$. It incorporates true responses and false alarms to minimize the effects of response bias to target and non-target stimuli. The d-prime statistic was calculated as the difference between $\mathrm{Z}$ scorers for hit rates and false alarms [i.e., d-prime $=Z$ (hit rate) $Z$ (false alarm rate) $]$ for the total 120 trials and for the three stimulus pair types. The differences between each pair type were analyzed using a one-way repeated measures ANOVA. We were also interested in the ability to discriminate pairs as learning occurred across time, therefore data was subdivided into blocks of five trials each; there were a total of 24 successive blocks. Preliminary analyses revealed that d-prime values for block 8 and all subsequent blocks violated normality, thus analysis of the effects of task and stimulus pair type across the first 7 blocks were assessed using a 3 (task: novel-AV, verbal-AV, shape-AV) $\times 7$ (block: 1, 2, 3, $4,5,6,7)$ repeated measures ANOVA.

Changes in MRTs with learning were also investigated. Based on learning trends observed in the moving average learning curves (see Figure 3), the first 20 matching trials were defined as the "learning" phase and final 20 target trials were defined as the "learnt" phase (please note that non-target stimuli did not require a response, hence could not be included in this analysis). Differences in learning between tasks were assessed using a 3 (task: novel-AV, verbal-AV, shape $-\mathrm{VV}) \times 2$ (phase of learning: learning, learnt) repeated measures ANOVA.

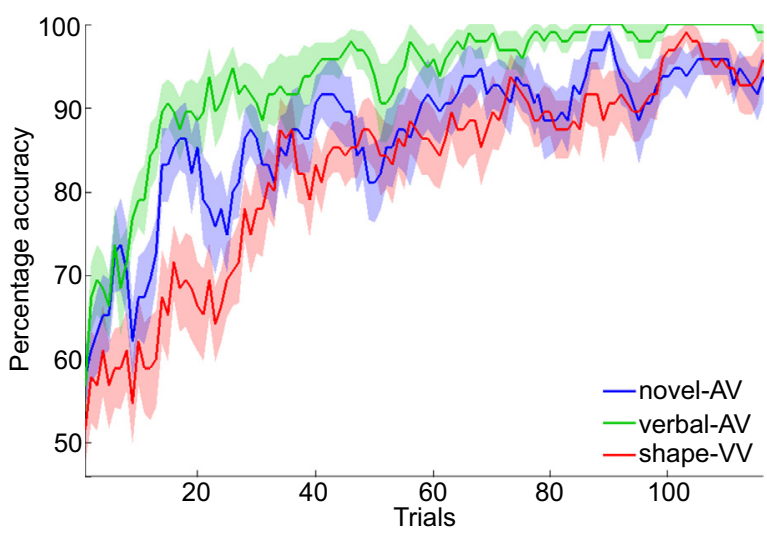

Figure 3. Percentage accuracy for the associative learning tasks. Moving average of mean percentage accuracy for trials on the novelsound auditory-visual (novel-AV), the verbal-visual (verbal-AV), and the visual-visual with red shapes (shape-VV) learning tasks. Shaded areas depict SEM along the moving average.

All significant main effects obtained in ANOVA analyses were followed up with post-hoc pairwise comparisons using Tukey corrections. For all statistical tests, alpha level was set at 0.05 .

\section{Results}

Analysis of learning across time

Participants demonstrated learning in all three experimental tasks (see Figure 3). It can be seen that under all conditions, initial performance was close to chance levels, and accuracy rates above 90 percent were attained on each task. The verbal-AV task was consistently performed with greater accuracy than both non-verbal tasks, with a steeper trajectory of learning and with accuracy rates reaching ceiling performance during the second half of the experiment. Of the non-verbal tasks, the novel-AV task tended to be performed with slightly greater accuracy than the shape-VV task. This novel-AV superiority was primarily evident at early learning stages; novel-AV and shape-VV accuracy rates were more similar from trial 50 onwards.

Similar effects of task were evident when d-prime measures were considered. Overall mean discriminability (d-prime) significantly differed across all stimulus conditions, (see Figure 4A), $F(2,38)=16.77, p<0.001$. The mean d-prime value for the verbal$\mathrm{AV}$ task was significantly higher than that for the novel-AV, both of which were significantly higher than the shape-VV task.

Analyses of discriminability across early blocks (Figure 4B) revealed that there were no discernable differences in the patterns of learning for each task, as the interaction between task and block was not significant, $F(12,216)=1.54, p>0.01$. However, it was found that overall discriminability measures for the three task types significantly differed across these first 7 blocks, $F(2,216)=22.40$, $p<0.001$. Performance rates were significantly different between all tasks, with verbal-AV producing the greatest discriminabilty and 
A

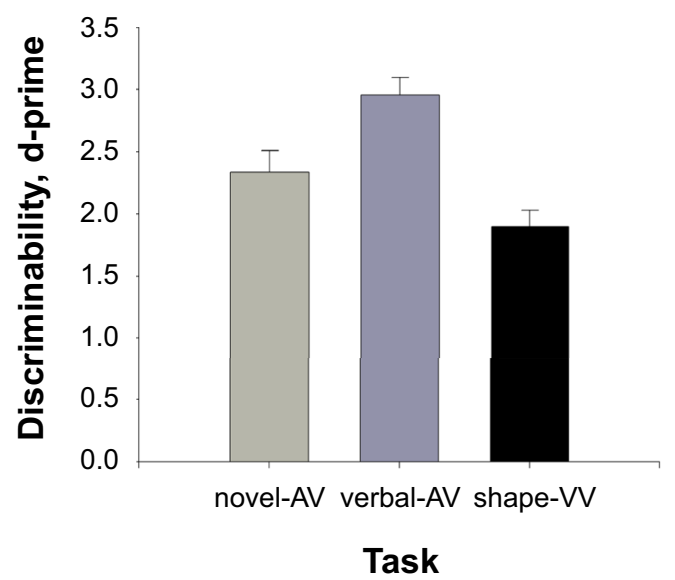

B

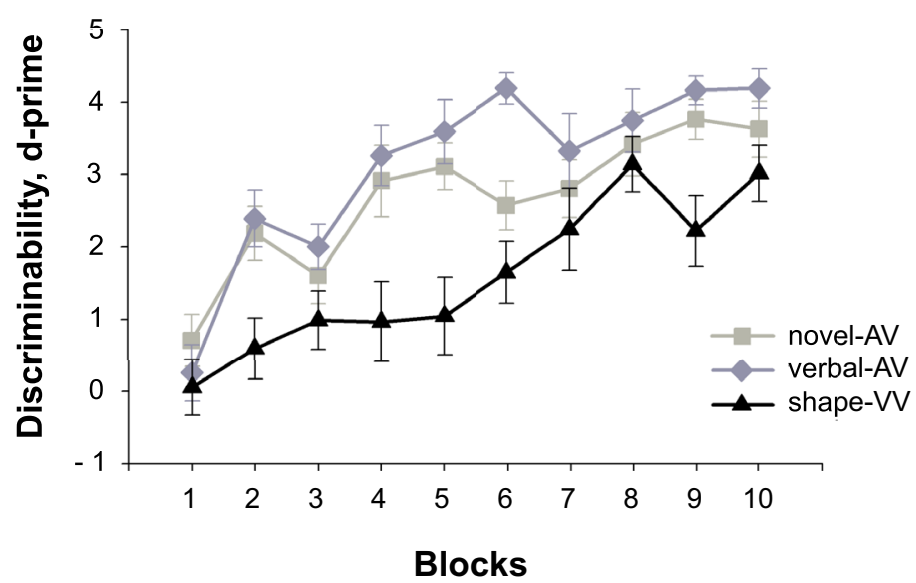

Figure 4. Discriminability measures for associative learning tasks. A. Overall mean discriminability (d-prime) ( \pm SEM) for the novel-sound auditory-visual (novel-AV), the verbal-visual (verbal-AV), and the visual-visual with red shapes (shape-VV) learning tasks. B. Discriminability (d-prime) first 10 blocks of trials on the novel-AV, the verbal-AV, and the shape-VV learning tasks. Each block comprised 5 consecutive trials.

shape-VV the poorest. In addition, with all tasks considered, mean d-prime measures significantly increased between the first two blocks, and then significant increases in discriminability occurred at block 5 before plateauing thereafter $F(6,216)=13.45, p<0.001$.

\section{Experiment 1 raw data}

http://dx.doi.org/10.6084/m9.figshare.154796

Motor reaction time analyses

As can be observed in Figure 3, moving averages of percent accuracy show steep learning trends within the first 20 trials with performance almost reaching ceiling levels by the end of the first 60 trials. We therefore further investigated differences in motor responses during the learning stage (first 20 trials) and the late learning stage (41-60 trials) for matching stimuli (note that nonmatching stimuli did not require a response, hence, non-matching trials could not be included in the MRT analyses). A significant interaction effect between learning phase and task type was found, $F(2,36)=3.56, p<0.05$, partial $\eta^{2}=0.17$. At both learning stages, the MRTs for the verbal-AV condition were significantly faster than for the novel-AV and shape-VV tasks (see Figure 5); the MRTs for novel-AV and shape-VV tasks did not differ significantly from each other in the first 20 target trials. Furthermore, the rate of change in MRTs was significantly greater for verbal-AV trials compared with shape-VV trials. The change in MRTs for novel-AV trials did not significantly differ from either verbal-AV or shape-VV trials.

\section{Discussion}

The results of Experiment 1 demonstrated a significant advantage for the learning of both verbal and non-verbal auditory-visual stimulus associations over intra-modal visual-visual associations. In the verbal-visual task, associated stimuli were also identified faster. Whilst these results represent potentially important and compelling findings, it remained difficult to delineate the underlying factors causing the learning differences. The most pressing factor was the

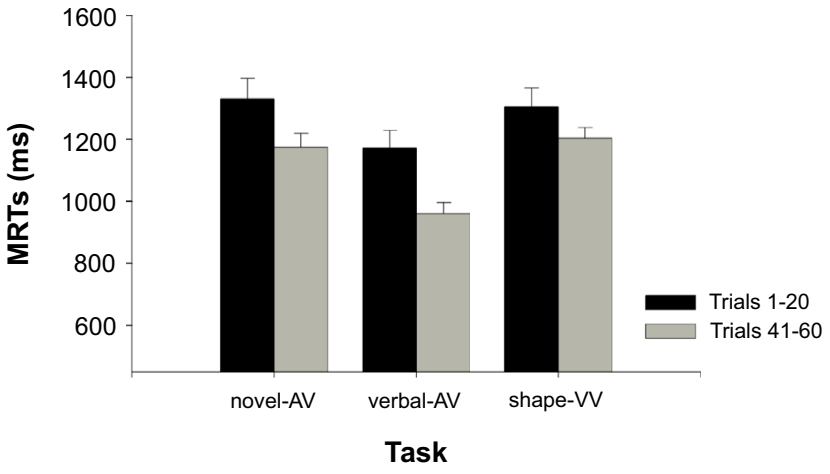

Figure 5. Reaction times for associative learning tasks. Average motor reaction times (MRTs) ( \pm SEM) for the learning phase (Trials 1-20) and the learnt phase (Trials 41-60) in the novel-sound auditory visual (novel-AV), verbal-visual (verbal-AV), and visual-visual (shape-AV) learning tasks.

possible confounding influence of differences in stimulus discriminability at a unisensory level. A follow-up experiment evaluated whether unequal unisensory stimulus discriminability could explain differences in learning trends between the verbal-AV, novel-AV and shape-VV tasks.

\section{Experiment 2}

The aim of Experiment 2 was to investigate whether the unisensory auditory and visual stimuli employed in the associative learning paradigms differ in discrimination difficulty. The auditory and visual stimulus sets from the learning tasks were tested in six separate forced-choice discrimination tasks (see Figure 1 for an illustration of all 6 stimulus sets). Here we investigated discrimination difficulty across the three differing task-specific stimuli: novel auditory stimuli (novel-A), verbal auditory stimuli (verbal-A), and red-shape visual stimuli (shape-V), in addition to the three sets of visual black symbols that were paired with: BS1, BS2 and BS3, respectively. 


\section{Method}

Participants

Participants were 12 adult volunteers ( 6 males), aged between 18 and 35 years $(M=29.55, S D=3.43)$. Participants who took part in the current control study did not participate in the learning task. All participants were right handed, had normal or corrected to normal vision, normal hearing and no prior history of neurological or psychiatric disorders.

\section{Stimuli and discrimination tasks}

The forced-choice discrimination tasks utilised the six stimulus sets that were employed in the three learning tasks in Experiment 1: novel sounds (novel-A), verbal pseudowords (verbal-A), red shapes (shape-V), BS1, BS2 and BS3 (see Figure 1 for an illustration of stimuli). There were four stimuli in each discrimination task, and for each task, one of the four stimuli was randomly assigned as the "target" stimulus, and the remaining three stimuli as "non-target" stimuli. The target stimuli were alternated via counterbalancing across participants such that each stimulus acted as the target stimulus on an equal number of occasions.

Stimuli were presented individually in the discrimination tasks. Visual stimuli were presented at central fixation on a 17-inch laptop screen at three degrees of visual angle. Auditory stimuli were presented via closed headphones. Both the auditory and visual stimuli were presented for $\sim 620 \mathrm{~ms}$ duration. All other stimulus parameters for the novel sounds, verbal psuedowords, red shapes and visual black symbols (BS1, BS2 and BS3) were same as in Experiment 1.

For each task, participants were presented with 80 stimuli in two blocks of 40 trials each. The inter-stimulus interval (ISI) randomly varied between 1000-1500 ms during which a central fixation point was presented. Consistent with the learning tasks in Experiment 1, stimuli were presented in a pseudorandom order with a 0.5 target probability. The remaining stimuli consisted of non-targets with an equal probability of each type. The same stimulus was not presented for more than two consecutive trials. Participants were asked to indicate whether the stimuli were targets or non-targets by pressing buttons on a keyboard. A feedback tone pip $(700 \mathrm{~Hz}, 122 \mathrm{~ms}$ in duration) was provided at the end of a trial if the response was incorrect.

\section{Procedure}

All participants completed the six discrimination tasks. The order of task administration was counterbalanced across participants to negate any order or practice effects. Participants were instructed to press the left arrow key on a standard keyboard with their index finger in response to a target, and the right arrow key with their middle finger in response to any non-target stimuli. Participants were instructed to respond as quickly and accurately as possible. A feedback tone pip was provided when the participant's response was incorrect; no feedback was provided for a correct response. Prior to testing, participants were given up to 20 trials as practice during which they were familiarised with the target stimulus and were able to practice performing the task.

\section{Data analysis}

Percentage error and mean MRTs for target and non-target stimuli were calculated. All participants completed 80 trials; whilst a lowerbound response inclusion criterion of $150 \mathrm{~ms}$ was set to control for response anticipation, there were no responses of this nature, so no data was excluded on this basis.

For MRTs, two repeated measures ANOVAs were used to analyse differences between novel sounds, verbal pseudowords and visual shapes, and the three black symbol sets separately. Any significant effects were followed up with Tukey post-hoc tests.

\section{Results}

The percentage error rates for all discrimination paradigms were very low, averaging below $6 \%$ error rates (see Table 1). Many participants did not make discrimination errors, leading to violations of normality. Therefore, accuracy measures were not subjected to further data analyses.

The MRTs for the novel-A, verbal-A and shape-V discrimination stimuli significantly differed from each other (see Figure 6), $F(2$, $22)=26.58, p<0.001$, partial $\eta^{2}=0.71$. MRTs were significantly slower for verbal auditory stimuli (verbal-A) than both novel auditory (novel-A) and visual red shape (shape-V) stimuli. However, the MRTs for novel-A and shape-V stimuli did not significantly differ from each other. No significant differences were found between MRTs for the three black symbol sets, $F(2,22)=1.36, p>0.05$, partial $\eta^{2}=0.11$.

Experiment 2 raw data

http://dx.doi.org/10.6084/m9.figshare.154797

\section{Discussion}

All auditory and visual stimuli were relatively easy to discriminate. Differences in discrimination difficulty were minimal with accuracy measures being at ceiling for all stimulus types. Although motor reaction times did not significantly differ between the black symbol

\begin{tabular}{|c|c|c|c|c|c|c|c|c|}
\hline \multicolumn{5}{|c|}{ Task Specific Stimuli } & \multicolumn{4}{|c|}{ Black Symbol Sets } \\
\hline & & Mean & Med & $S D$ & & Mean & Med & $S D$ \\
\hline Novel-A & Target & 4.48 & 2.50 & 4.38 & BS1 & 3.54 & 2.5 & 4.32 \\
\hline Verbal-A & Target & 2.92 & 2.50 & 2.57 & BS2 & 4.27 & 3.75 & 3.59 \\
\hline Shape-V & Target & 5.10 & 4.38 & 3.82 & BS3 & 2.50 & 1.25 & 3.59 \\
\hline
\end{tabular}




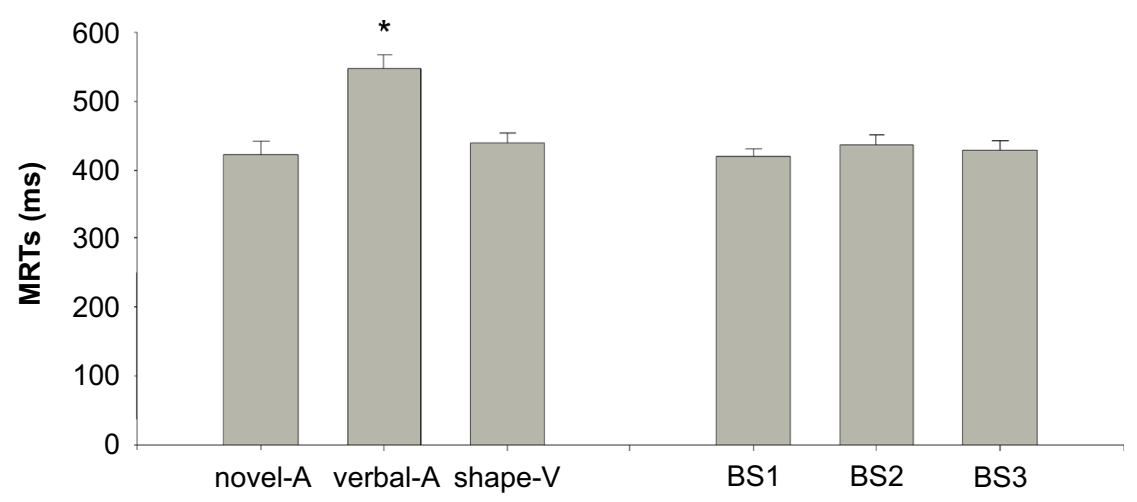

Figure 6. Reaction times for unisensory stimulus discrimination. Mean MRTs (+SEM) for each of the discrimination tasks: novel auditory sounds (novel-A), verbal auditory sounds (verbal-A), visual red shapes (shape-V), and the black visual symbol sets (BS1, BS2 and BS3). ${ }^{*} p<0.05$.

sets, motor responses were significantly slower for verbal stimuli compared with the novel auditory stimuli and the red shape stimuli. This finding is consistent with prior studies suggesting that verbal stimuli require longer processing times than visual pictures ${ }^{19}$. Nevertheless, the high accuracy rates for all stimulus sets suggest that any differences in discrimination difficulty between stimulus sets are relatively small, with verbal stimuli being slower to process.

It may be argued that relative differences in the memorability of the unisensory stimuli, in addition to their discriminability, may have influenced performance in the three learning tasks in Experiment 1. However, successful performance of the current discrimination task in this experiment necessitated memory processing. An accurate and speedy response to the presented stimulus required the comparison of that stimulus to a memory trace of the "target" stimulus. Therefore, the lack of significant differences between discrimination accuracy and MRTs to the auditory and visual stimuli suggests that the stimuli did not differ in their discriminability or memoriability.

\section{General discussion}

The current results provide new evidence regarding the differences between multisensory and intra-modal learning, with more accurate performances and faster learning on the verbal-visual and novel auditory-visual tasks compared with the visual-visual task, suggesting that multisensory processing facilitates associative learning. The enhanced speed of response during the learning of verbal-visual associations compared with non-verbal stimulus associations suggest that verbal information further facilitates the associative learning process. The results of Experiment 2 suggested that the obtained task-related learning effects represented differences in associative learning rather than relative differences in stimulus discriminability between auditory and visual stimuli.

An enhancement in the learning of multisensory stimuli relative to intra-modal stimuli is not unexpected given that multisensory processing has long been known to facilitate information processing ${ }^{32}$. This facilitative effect has been shown to be substantially greater for multisensory stimulus combinations than for multiple stimuli within a single modality ${ }^{33}$. Not only do multisensory processes facilitate memory ${ }^{7}$, but they have also been shown to enhance perceptual and implicit learning, and training outcomes ${ }^{11,12,34-36}$. Consistent with these prior findings, the results of the present study indicate that this multisensory advantage extends to paired associative learning. Novel auditory-visual and verbal-visual tasks were performed with greater levels of discrimination during learning compared with the visual-visual task. Motor responses were also faster with the learning of multisensory rather than unisensory stimuli, even though the motor reaction times did not significantly differ during early stages of learning of the novel auditory-visual and unisensory visual tasks. These significant learning results were in the context of non-significant differences in motor responses between stimuli employed in the novel-AV and shape-VV tasks.

The afore-mentioned multisensory enhancement of learning contrasted with the behavioural findings of Tanabe et al. ${ }^{20}$. The differences between the results of our study and those of the fMRI study of Tanabe et al..$^{20}$ may be explained by the fact that they presented stimulus pairs sequentially, 15 seconds apart, whilst we presented stimulus pairs simultaneously. The temporally concurrent presentation of multisensory stimuli would maximise the likelihood that multisensory 'integrative' processes are engaged. Animal studies using single-cell recordings have demonstrated that up-regulation of neural activation occurs only when stimuli are presented within a temporal window of $500 \mathrm{~ms}^{37}$. Similarly, behavioural facilitation in humans is observed only when auditory and visual stimuli are presented in close spatial and temporal proximity (reviewed in Spence and Squire ${ }^{38}$ and Wallance et al. ${ }^{39}$ ). An alternative explanation is that our concurrent presentation may have emphasised differences in salience and attentional resources within and across sensory modalities during dual stimulus presentations. Whilst concurrent stimulus presentations within the one modality (e.g., auditory-auditory or visual-visual) can have an interfering effect on stimulus perception, there is no such performance decrement when two concurrent stimuli are presented across different modalities (i.e., auditoryvisual), even when stimuli are semantically incongruent ${ }^{13,40}$. Thus, the concurrent presentation of stimuli in the present study is likely to have facilitated information processing via modulation of either 
integrative or attentional processes, resulting in enhanced learning of novel multisensory stimulus pairs.

Whilst both novel auditory-visual and verbal-visual tasks were associated with superior learning performances compared to the visual-visual task, additional performance gains were observed in the verbal-visual task. Both d-prime analyses indicated that greater discrimination of learned pairs was achieved in the verbal-visual task relative to the novel auditory-visual task, and the MRTs were significantly faster in the verbal-visual task in Experiment 1, yet participants were significantly slower at discriminating unisensory verbal stimuli in Experiment 2. These verbal-visual findings are noteworthy, given that the verbal stimuli used in all learning tasks in the present study were novel and therefore lacked semantic content. The only familiar or categorisable aspect of the verbal stimuli was the phonetic and verbalisable nature of the pseudowords, which allow for quicker encoding and rehearsal of the auditory stimulus component $^{41,42}$. The visual-verbal learning advantage was evident despite the fact that participants were significantly slower at discriminating the individual verbal stimuli than the novel sounds and visual shapes. This finding is consistent with prior studies showing that verbal information requires longer time to processes than visual pictures ${ }^{19}$. Thus, the observed enhancements for verbal-visual associative learning cannot be attributed to a possible imbalance in discrimination difficulty between tasks; rather it appears that the processing speed advantage in the verbal-AV task is most likely related to a verbal-visual learning enhancement. This result suggests that verbal information is likely to play an important role in facilitating the accuracy and speed of human learning.

From an early age (and throughout life) we assign arbitrary, speech-based labels to visual stimuli encountered in the environment. Even though the verbal stimuli in this study were not known words, the task reflects a common requirement of daily life, which often involves previously non-encountered words to be learnt and associated with an object or person (e.g., surnames, technical or scientific terms). Similarly, in infants, nonsense words have been shown to enhance associations between stimuli and contribute to categorical learning ${ }^{27,28}$. Verbal stimuli have also been shown to enhance other cognitive processes in adults, such as object categorization $^{22,23}$. The known role of the superior temporal sulcus (STS) in performing speech and language-based functions in addition to multisensory auditory-visual integration may suggest that it plays a role in subserving this necessary skill ${ }^{20,43-46}$. Other studies have also shown greater levels of activation to multisensory stimuli involving phonetic elements in STS compared with novel auditory-visual stimuli $^{1,47}$. Thus, it is likely that different neural networks underlie the processing of verbal-visual stimuli and non-verbal novel auditory-visual stimuli.

In conclusion, the present study revealed two major influences on paired associative learning. Firstly, improvements in accuracy and MRTs were demonstrated in multisensory learning tasks compared with the visual-visual learning task, and secondly, further gains in performance were obtained when auditory stimuli contained a verbal component. These results indicate that multisensory integration can facilitate associative learning, and provides new evidence that this facilitation may be further enhanced by verbal content.

\section{Author contributions}

JMF conceptualized the project and developed the project proposal in consultation with AB, MNS and SGC. MNS programmed the experiments with input from JMF and AB. JMF collected the all the data. All authors contributed to data analysis, interpretation and the writeup of the manuscript. All authors reviewed and approved the final manuscript.

\section{Competing interests}

No competing interests have been declared.

\section{Grant information}

We wish to thank Neville and Di Bertalli for their financial support of this study. The Bionics Institute acknowledges the support it receives from the Victorian Government through its Operational Infrastructure Support Program.

The funders had no role in study design, data collection and analysis, decision to publish, or preparation of the manuscript.

\section{Acknowledgements}

We would also like to thank Prof Antonio Paolini (School of Psychological Science, La Trobe University), Dr David Grayden (Electrical and Electronic Engineering, University of Melbourne) and Hamish Innes-Brown (Bionics Institute) for their support.
1. Raij $\mathrm{T}$, Uutela $\mathrm{K}$, Hari R: Audiovisual integration of letters in the human brain. Neuron. 2000; 28(2): 617-625.

PubMed Abstract | Publisher Full Text

2. Beauchamp MS, Lee KE, Argall $\mathrm{BD}$, et al.: Integration of auditory and visual information about objects in superior temporal sulcus. Neuron. 2004; 41(5): 809-823.

PubMed Abstract | Publisher Full Text

3. Noppeney $\mathrm{U}$, Josephs $\mathrm{O}$, Hocking $\mathrm{J}$, et al.: The effect of prior visual information on recognition of speech and sounds. Cereb Cortex. 2008; 18(3): 598-609. PubMed Abstract | Publisher Full Text

4. Miller J: Divided attention: evidence for coactivation with redundant signals.
Cogn Psychol. 1982; 14(2): 247-279.

PubMed Abstract | Publisher Full Text

5. Lovelace CT, Stein BE, Wallace MT: An irrelevant light enhances auditory detection in humans: a psychophysical analysis of multisensory integration in stimulus detection. Brain Res Cogn Brain Res. 2003; 17(2): 447-453.

PubMed Abstract | Publisher Full Text

6. Barutchu A, Crewther SG, Fifer J, et al.: The relationship between multisensory integration and IQ in children. Dev Psychol. 2011; 47(3): 877-885. PubMed Abstract | Publisher Full Text

7. Murray MM, Michel CM, Grave de Peralta R, et al:: Rapid discrimination of visual and multisensory memories revealed by electrical neuroimaging. Neuroimage. 
2004; 21(1): 125-135

PubMed Abstract | Publisher Full Text

8. Lehmann S, Murray MM: The role of multisensory memories in unisensory object discrimination. Brain Res Cogn Brain Res. 2005: 24(2): 326-334. PubMed Abstract | Publisher Full Text

9. Beer AL, Batson MA, Watanabe $\mathrm{T}$ : Multisensory perceptual learning reshapes both fast and slow mechanisms of crossmodal processing. Cogn Affect Behav Neurosci. 2011; 11(1): 1-12.

PubMed Abstract | Publisher Full Text | Free Full Text

10. Beer $A L$, Watanabe $T$ : Specificity of auditory-guided visual perceptual learning suggests crossmodal plasticity in early visual cortex. Exp Brain Res. 2009; 198(2-3): 353-361

PubMed Abstract | Publisher Full Text | Free Full Text

11. Kim RS, Seitz AR, Shams L: Benefits of stimulus congruency for multisensory facilitation of visual learning. PLoS One. 2008; 3(1): e1532.

PubMed Abstract | Publisher Full Text | Free Full Text

12. Seitz AR, Kim R, Shams L: Sound facilitates visual learning. Curr Biol. 2006; 16(14): 1422-1427.

PubMed Abstract | Publisher Full Text

13. Larsen A, Mcllhagga W, Baert J, et al:: Seeing or hearing? Perceptua independence, modality confusions, and crossmodal congruity effects with focused and divided attention. Percept Psychophys. 2003; 65(4): 568-574. PubMed Abstract | Publisher Full Text

14. Laurienti PJ, Kraft RA, Maldjian JA, et al: Semantic congruence is a critical factor in multisensory behavioral performance. Exp Brain Res. 2004; 158(4): 405-414. PubMed Abstract | Publisher Full Text

15. Molholm S, Ritter W, Javitt DC, et al.: Multisensory visual-auditory object recognition in humans: a high-density electrical mapping study. Cereb Cortex. 2004; 14(4): 452-465.

PubMed Abstract | Publisher Full Tex

16. Laine M, Kwon MS, Hämäläinen H: Automatic auditory change detection in humans is influenced by visual-auditory associative learning. Neuroreport. 2007; 18(16): 1697-1701. PubMed Abstract | Publisher Full Tex

17. Naumer MJ, Doehrmann O, Muller NG, et al:: Cortical plasticity of audio-visual object representations. Cereb Cortex. 2009; 19(7): 1641-1653.

PubMed Abstract | Publisher Full Text | Free Full Text

18. Fiebelkorn IC, Foxe JJ, Molholm S: Dual mechanisms for the cross-sensory spread of attention: how much do learned associations matter? Cereb Cortex. 2010; 20(1): 109-120.

PubMed Abstract | Publisher Full Text | Free Full Text

19. Chen YC, Spence C: Crossmodal semantic priming by naturalistic sounds and spoken words enhances visual sensitivity. J Exp Psychol Hum Percept Perform 2011; 37(5): 1554-1568.

PubMed Abstract | Publisher Full Text

20. Tanabe HC, Honda M, Sadato N: Functionally segregated neural substrates for arbitrary audiovisual paired-association learning. J Neurosci. 2005; 25(27) 6409-6418.

PubMed Abstract | Publisher Full Text

21. Puce A, Epling JA, Thompson JC, et al:: Neural responses elicited to face motion and vocalization pairings. Neuropsychologia. 2007; 45(1): 93-106. PubMed Abstract | Publisher Full Text | Free Full Text

22. Lupyan G, Thompson-Schill SL: The evocative power of words: activation of concepts by verbal and nonverbal means. J Exp Psychol Gen. 2012; 141(1): 170-186. PubMed Abstract | Publisher Full Text

23. Lupyan G, Spivey MJ: Redundant spoken labels facilitate perception of multiple items. Atten Percept Psychophys. 2010; 72(8): 2236-2253. PubMed Abstract | Publisher Full Text

24. Windfuhr KL, Snowling MJ: The relationship between paired associate learning and phonological skills in normally developing readers. J Exp Child Psychol. 2001; 80(2): 160-173.

PubMed Abstract | Publisher Full Text

25. Thomson B, Crewther DP, Crewther SG: Wots that werd? Pseudowords (nonwords) may be a misleading measure of phonological skills in young learner readers. Dyslexia. 2006; 12(4): 289-299. PubMed Abstract | Publisher Full Text

26. Hulme C, Goetz K, Gooch D, et al:: Paired-associate learning, phoneme awareness, and learning to read. J Exp Child Psychol. 2007; 96(2): 150-166. PubMed Abstract | Publisher Full Tex
27. Waxman SR, Markow DB: Words as invitations to form categories: evidence from 12- to 13-month-old infants. Cogn Psychol. 1995; 29(3) 257-302.

PubMed Abstract | Publisher Full Text

28. Fulkerson AL, Waxman SR: Words (but not tones) facilitate object categorization: evidence from 6- and 12-month-olds. Cognition. 2007; 105(1): 218-228

PubMed Abstract | Publisher Full Text | Free Full Text

29. Wechsler D: Wechsler Test of Adult Reading. San Antonio, TX: The Psychological Corporation 2001.

30. Macmillan NA, Creelman CD: Detection theory: A user's guide. Cambridge: Cabridge University Press 2004

Reference Source

31. Sternberg S: Modular processes in mind and brain. Cogn Neuropsychol. 2011; 28(3-4): 156-208.

PubMed Abstract | Publisher Full Text

32. Todd JW: Reaction to multiple stimuli. Archives of Psychology. 1912; 25: 1-65. Reference Source

33. Gingras G, Rowland BA, Stein BE: The differing impact of multisensory and unisensory integration on behavior. J Neurosci. 2009; 29(15): 4897-4902. PubMed Abstract | Publisher Full Text | Free Full Text

34. Alais D, Cass J: Multisensory perceptual learning of temporal order: audiovisual learning transfers to vision but not audition. PLOS One. 2010; 5(6): e11283.

PubMed Abstract | Publisher Full Text | Free Full Text

35. Seitz AR, Kim R, van Wassenhove V, et al.: Simultaneous and independent acquisition of multisensory and unisensory associations. Perception. 2007; 36(10): 1445-1453.

PubMed Abstract | Publisher Full Text

36. Ernst MO: Learning to integrate arbitrary signals from vision and touch. J Vis. 2007; 7(5): 7.1-14.

PubMed Abstract | Publisher Full Text

37. Wallace MT, Wilkinson LK, Stein BE: Representation and integration of multiple sensory inputs in primate superior colliculus. J Neurophysiol. 1996; 76(2): 1246-1266.

PubMed Abstract

38. Spence $C$, Squire S: Multisensory integration: maintaining the perception of synchrony. Curr Biol. 2003; 13(13): R519-521. PubMed Abstract | Publisher Full Text

39. Wallace MT, Roberson GE, Hairston WD, et al:: Unifying multisensory signals across time and space. Exp Brain Res. 2004; 158(2): 252-258. PubMed Abstract | Publisher Full Text

40. Alais D, Morrone C, Burr D: Separate attentional resources for vision and audition. Proc Biol Sci. 2006; 273(1592): 1339-1345.

PubMed Abstract | Publisher Full Text | Free Full Text

41. Roberts LA: Modality and suffix effects in memory for melodic and harmonic musical materials. Cogn Psychol. 1986; 18(2): 123-157. PubMed Abstract | Publisher Full Text

42. Keller TA, Cowan N, Saults JS: Can auditory memory for tone pitch be rehearsed? J Exp Psychol Learn Mem Cogn. 1995; 21(3): 635-645. PubMed Abstract | Publisher Full Text

43. Calvert GA, Hansen PC, Iversen SD, et al.: Detection of audio-visual integration sites in humans by application of electrophysiological criteria to the BOLD effect. Neuroimage. 2001; 14(2): 427-438. PubMed Abstract | Publisher Full Text

44. Werner S, Noppeney U: Distinct functional contributions of primary sensory and association areas to audiovisual integration in object categorization. $J$ Neurosci. 2010; 30(7): 2662-2675. PubMed Abstract | Publisher Full Tex

45. Meyer GF, Wuerger S, Greenlee M: Interactions between Auditory and Visua Semantic Stimulus Classes: Evidence for Common Processing Networks for Speech and Body Actions. J Cogn Neurosci. 2011; 23(9): 2291-308. PubMed Abstract | Publisher Full Text

46. Hein G, Knight RT: Superior temporal sulcus-It's my area: or is it? J Cogn Neurosci. 2008; 20(12): 2125-2136. PubMed Abstract | Publisher Full Text

47. van Atteveldt N, Formisano E, Goebel R, et al:: Integration of letters and speech sounds in the human brain. Neuron. 2004; 43(2): 271-282. PubMed Abstract | Publisher Full Text 


\section{Open Peer Review}

\section{Current Peer Review Status:}

\section{Version 2}

Reviewer Report 23 January 2014

https://doi.org/10.5256/f1000research.1396.r1595

(c) 2014 Hine T. This is an open access peer review report distributed under the terms of the Creative Commons Attribution License, which permits unrestricted use, distribution, and reproduction in any medium, provided the original work is properly cited.

\section{Trevor Hine}

Griffith University, Queensland, Australia

Competing Interests: No competing interests were disclosed.

I confirm that I have read this submission and believe that I have an appropriate level of expertise to confirm that it is of an acceptable scientific standard.

\section{Version 1}

Reviewer Report 26 March 2013

https://doi.org/10.5256/f1000research.904.r864

(C) 2013 Hine T. This is an open access peer review report distributed under the terms of the Creative Commons Attribution License, which permits unrestricted use, distribution, and reproduction in any medium, provided the original work is properly cited.

\section{Trevor Hine}

Griffith University, Queensland, Australia

Two well-run experiments: the first of which shows important differences not just in the rate of cross-modal vs uni-modal learning, but also in the processing speed involved in recognising these learned associations. The second experiment is an important control for the discriminability and processing speed for stimuli used in the first experiment. Together, this shows that the effects in the first experiment of learning simultaneously paired associations are due to genuine crossmodal facilitation. Other minor points: 
Page 4. Calculation of d-prime does not involve just the 'hit' and 'false alarm' frequencies, but also 'misses' and 'correct rejections' frequencies. Given this, it would be helpful if the authors made it more explicit how they calculated d-prime from your raw data.

Page 7.In the sentence 'No significant differences were found between MRTs for the three black symbol sets, $F(2,22)=1.36, p<.05$, partial $\eta 2=.11$.' There is a typo ' $p>.05$ '.

Competing Interests: No competing interests were disclosed.

\section{I confirm that I have read this submission and believe that I have an appropriate level of expertise to confirm that it is of an acceptable scientific standard.}

Author Response 29 Apr 2013

Sheila Crewther, La Trobe University, Bundoora, Australia

Dear Dr Hine,

Thank you for picking up the typo and highlighting the ambiguity regarding d-prime.

Indeed d-prime involves misses and correct rejection frequencies. In our case we calculated d-prime as the difference between 'hit' and 'false alarm' z scores [i.e, d-prime $=$ Z(hit rate) Z(false alarm rate)].

Regards Sheila Crewther. PhD

Competing Interests: No competing interests were disclosed.

Reviewer Report 14 February 2013

https://doi.org/10.5256/f1000research.904.r768

(C) 2013 Baker C. This is an open access peer review report distributed under the terms of the Creative Commons Attribution License, which permits unrestricted use, distribution, and reproduction in any medium, provided the original work is properly cited.

\section{Chris Baker}

Laboratory of Brain and Cognition, National Institute of Mental Health, National Institutes of Health, Bethesda, MD, USA

Competing Interests: No competing interests were disclosed.

I confirm that I have read this submission and believe that I have an appropriate level of expertise to confirm that it is of an acceptable scientific standard. 
The benefits of publishing with F1000Research:

- Your article is published within days, with no editorial bias

- You can publish traditional articles, null/negative results, case reports, data notes and more

- The peer review process is transparent and collaborative

- Your article is indexed in PubMed after passing peer review

- Dedicated customer support at every stage

For pre-submission enquiries, contact research@f1000.com 